GABA-GABA: Jurnal Pengabdian Masyarakat

dalam bidang Pendidikan Bahasa dan Seni

Vol. 1 No. 2, November 2021, Hal 49-55

e-ISSN : 2797-8494

\title{
PEMAHAMAN PENERAPAN AKM (ASESMEN KOMPETENSI MINIMAL) BAGI GURU-GURU DI KEC. SALAHUTU KAB. MALUKU TENGAH
}

\author{
Helena Magdalena Rijoly, S.Pd., MA ELT ${ }^{1}$, Jusak Patty, S.Pd., M.Pd ${ }^{2}$ \\ ${ }^{1}$ Program Studi Pendidikan Bahasa Inggris, FKIP, Unpatti \\ rijolyhelenadell@gmail.com \\ ${ }^{2}$ Program Studi Pendidikan Bahasa Inggris, FKIP, Unpatti \\ jusak.patty@gmail.com
}

\begin{abstract}
Abstrak
Pemerintah Indonesia mengeluarkan kebijakan baru evaluasi Pendidikan di Indonesia dengan mencanangkan pelaksanaan Asesmen Nasional (AN) yang akan mengganti Ujian Nasional (UN). Pelaksanaannya dicanangkan untuk dimulai pada September 2021. Skema baru ini masih menimbulkan kebingungan pada guru-guru dan sekolah. Banyak sosialisasi dan pelatihan telah dilakukan, namun tentu saja belum mencakup seluruh daerah di Indonesia. Lewat program Pengabdian Kepada Masyarakat, Program Studi Pendidikan Bahasa Inggris menggelar sesi training mengenai Asesmen nasional dan instrument-instrumennya seperti Asesmen Kompetensi Minimum (AKM), Survei Karakter dan Survei Lingkungan Belajar. Kegiatan ini menargetkan para guru dan sekolah di Kec. Salahutu Kab. Maluku tengah. Pelatihan ini mengundang instruktur nasional untuk AN dan dihadiri oleh 40 orang peserta. Tujuan utama pelatihan ini adalah mengedukasi serta memberikan penguatan kapasitas kepada para guru dan sekolah mengenai ap aitu AN, AKM dan instrumen-intrumennya serta bagaimana penerapannya. Hasil evaluasi kegiatan menunjukan tingkat kepuasan yang tinggi dari para peserta.
\end{abstract}

Kata Kunci: Asesmen Nasional, AKM, Asesmen Kompetensi Minimal, Kesiapan Guru, Pelatihan Guru

\begin{abstract}
Indonesian government issued a new education evaluation policy with a new frame work called Asesmen Nasional or National Assessment. National Assessment will now be practiced in the place of Ujian Nasional or National Examination scheme. The new policy took place in September 2021. This new policy is very new and thus teachers and school management are not sure and felt not ready to implement this. There are already socialization and training taking place all over Indonesia but of course not all teachers and school are in full understanding of it. Therefore, English Education Study Program's Community Service program was focused to educate and to strengthen the capacity of teachers and school management in Salahutu Sub District of Central Maluku regent. The training focused in National Assessment and the three instruments: AKM (Minimum Competence Assessment), Character Survey and Learning Environment Survey. The program collaborated with the national instructor for AN. 40 teachers and school's officials were present. The feedback and evaluation result of the event shows a high satisfaction from the participants.
\end{abstract}

Keywords: National Assessments, AKM, Minimum Competence Assessment, Teacher Readiness, Teacher Training 


\section{PENDAHULUAN}

Salah satu penentu utama kelulusan siswa dari jenjang sekolah adalah Ujian Nasional (UN). Namun pada tahun 2021, pemerintah Indonesia mengganti pelaksanaan Ujian Nasional (UN) dengan Asesmen Nasional (AN). Salah satu alasan utama penggantian ini didasari kepada hasil assesmen dengan isntrumen penilaian skala internasional seperti PISA (programme for International Student Assessment) dan TIMSS (Trend in International Mathematic and Science Study). Hasil penilaian ini menunjukan bahwa Indonesia konsisten sebagai salah satu negara dengan peringkat PISA terendah dengan skor yang stagnan dalam 10-15 tahun terakhir (Rokhim, et al., 2021). Untuk itu dipandang perlu untuk meningkatkan sistem evaluasi pendidikan yang bertujuan untuk memperbaiki mutu pendidikan, pengalaman belajar mengajar dan tentu saja bermuara kepada hasil belajar yang lebih baik pula. Menteri Pendidikan dan Kebudayaan Republik Indonesia, bapak Nadiem A. Makarim, mengamanatkan bahwa , perubahan mendasar pada asesmen Nasional adalah tidak lagi mengevaluasi capaian peserta didik secara individu, akan tetapi mengevaluasi dan memetakan sistem pendidikan berupa input, proses dan hasil““ (Pusat Asesmen dan Pembelajaran, 2021).

Pemerintah kemudian mengeluarkan Permendikbudristek No. 17 tahun 2021 tertanggal 12 July 2021 tentang Asesmen Nasional (AN) yang mengatur bahwa Asesmen Nasional dirancang untuk memantau dan mengevaluasi sistem pendidikan dasar dan menengah, sedangkan prestasi siswa dievaluasi oleh pendidik dan satuan pendidikan (Kemdikbud, 2021). Asesmen Nasional menggunaan 3 instrumen yaitu: Asesmen Kompetensi Minimal (AKM), Survei karakter dan Survei Lingkungan Belajar. Instrumen Asesmen Kompetensi Minimal (AKM) bertujuan untuk mengukur litersi membaca dan numerasi sebagai hasil belajar kognitif. Instrumen Survei Karakter mengukur sikap, nilai, keyakinan dan kebiasaan yang mencerminkan karakter murid. Instrumen Survei Lingkungan Belajar mengukur kualitas pembelajaran dan iklim sekolah yang menunjang pembelajaran. Dengand demikian, Instrumen AKM dan Survei Karakter dilakukan kepada Peserta didik sementara Survey Lingkungan belajar ditujukan kepada sekolah untuk memperoleh informasi mengenai keadaan sekolah baik manajemen, sistem maunpun fasilitas dan infrastrukturnya. Informasi dan data yang diterima ini memberikan gambaran atau profil kekuatan dan kekurangan yang perlu ditingkatkan ditiap sekolah yang kemudian akan ditindak lanjuti oleh Kemdikbud dan dinas pendidikan.

Asesmen Nasional (AN) tahun 2021 dilaksanakan pada jenjang pendidikan SD/MI/SDLB sederajat (kelas 5 - maks. 30 siswa), SMP/MTs/SMPLB sederajat (kelas 8 maks. 45 siswa), SMA/MA/SMALB sederajat (kelas 11 - maks. 45 siswa)dan SMK/MAK (kelas 11 - maks. 45 siswa). Siswa-siswa yang akan mengikuti Asesmen Nasional (AN) dipilih dengan menggunakan sampel acak oleh Kemdikbud ditambah dengan 5 siswa cadangan untuk tiap jenjang. Asesmen Nasional (AN) ditetapkan untuk diikuti oleh Satuan pendidikan yang memiliki NPSN dan Tercatat di Kemdikbud, termasuk SPK dan SILN. Sedangkan untuk peserta dari sekolah berkebutuhan khusus akan difokuskan pada siswa di sekolah inklusi yang mampu mengerjakan asesmen secara mandiri. Dalam hal ini siswa SLB A, SLB B, SLB G tidah mengikuti AN. Selain siswa/peserta didik, Kepada satuan pendidikan (kepala sekolah) dan Pendidik (guru) juga mengikuti asesmen ini. 
Asesmen Nasional (AN) ini mulai digunakan pada tahun 2021. Sejak tahun 2020 Ditjen P3GTK Kementerian Pendidikan dan Kebudayaan (2020) telah melakukan banyak persiapan untuk penerapan Asesmen Nasional (AN). Kemudian pada 12 Juni 2020 - 24 Juli 2020 telah dilaksanakan uji coba instrumen Survei Karakter dan Survei Lingkungan Belajar pada 22 sekolah perwakilan dari Aceh hingga Papua. Demikian juga pelatihan-pelatihan master trainer (instruktur) untuk mensosialisasikan dan melatih para guru dan sekolah telah dilakukan. Instrumen-instrumen dan sistem Asesmen Nasional (AN) ini telah siap digunakan dan diterapkan pada tahun 2021.

Namun demikian, masih banyak guru dan sekolah yang masih belum sepenuhnya memahami tata cara penerapan Asesmen Nasional (AN) ini. Hal ini terjaring dalam proses Need Asesment yang dilakukan oleh tim pengabdian program studi pendidikan Bahasa Inggris sebagai bagian dari tahap awal penjajakan pelakasanaan pengabdian masyarakat. Need Asesment ini dilakukan untuk memastikan bahwa program atau kegiatan yang dilakukan tepat guna dan tetap sasaran sesuai dengan kebutuhan. Need Asesment dilakukan dengan menyebarkan Questionaire singkat yang bertujuan untuk menjaring topik-topik peningkatan kapasitas yang dibutuhkan oleh para guru di daerah sasaran. Ada 20 guru di Kecamatan Salahutu Kabupaten Maluku Tengah yang meresponi questionaire ini. Hasil need assesment menunjukan bahwa 50\% (10 orang) responden membutuhkan pelatihan tentang Asesmen Nasional. Hasil ini kemudian dikonfirmasi lebih lanjut lewat diskusi lewat Telpon dengan 1 orang kepala sekolah, 1 orang guru. Yang semakin memantapkan tim pengadian untuk mengangkat topik Pemahaman dan penerapan Asesmen Nasional (AN) sebagai kegiatan pengadian kepada masyarakat.

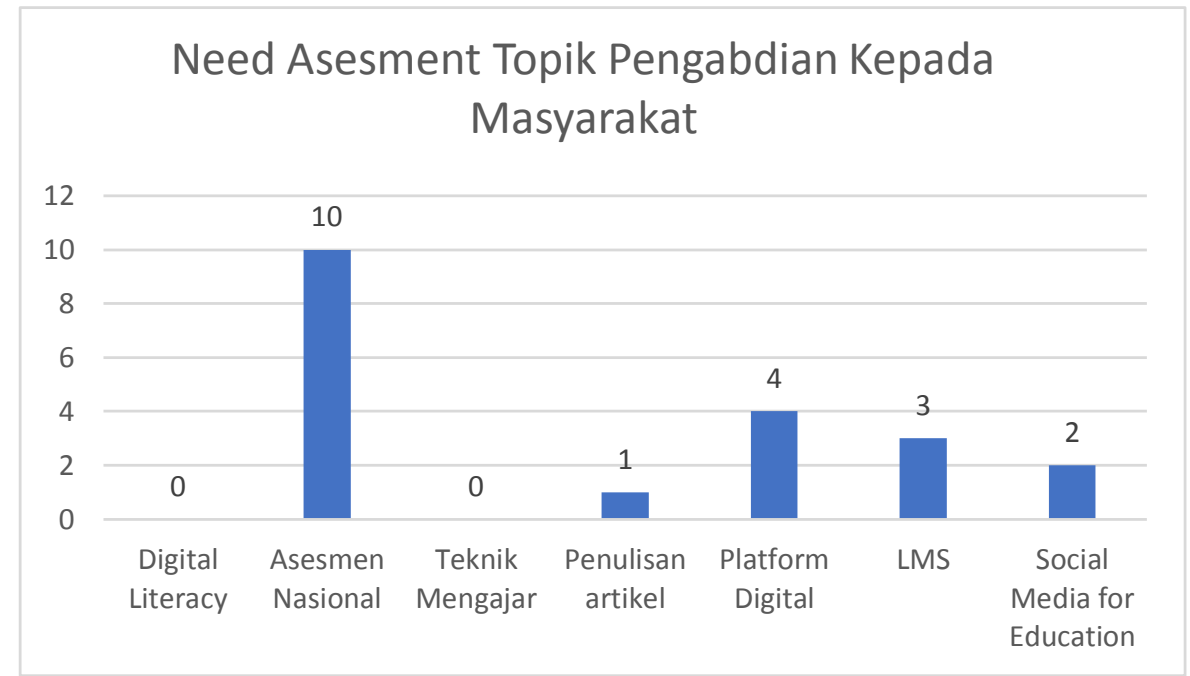

Gambar 1 Need Asesment Topik Pengadian Kepada Masyarakat

\section{METODE}

Program Studi Pendidikan Bahasa Inggris membagi dosen dan mahasiswa dalam beberapa kelompok untuk melaksanakan Pengadian kepada Masyarakat tahun 2021. Tim-tim tersebut tersebar di berbagai kabupaten dan kota diluar pusat kota Ambon. Kegiatan Pelatihan untuk Pemahaman Penerapan Asesmen Nasional ini dilaksanakan bagi guru-guru dan satuan pendidikan di Kecamatan Salahutu Kabupaten Maluku Tengah. Ada 4 tahapan pelaksanaan Pengadian kepada Masyarakat seperti dijelaskan dibawah ini: 


\subsection{Penjajakan}

Tahap penjajakan ini dilakukan dengan membangun komunikasi dengan guru dan anggota MGMP di lokasi sasaran. Kemudian menjalankan Need Assessment untuk mendapatkan data yang valid untuk memutuskan jenis program kegiatan yang akan dijalankan. Setelah mendapatkan informasi kebutuhan maka tim pengadian mulai untuk mempersiapkan kegiatan.

\subsection{Persiapan}

Pada tahap persiapan, tim pertama-tama merumuskan bentuk kegiatan. Kegiatan dibuat dalam bentuk Pelatihan yang bertujuan untuk mengedukasi serta memberikan penguatan kapasitas kepada guru-guru di daerah sasaran agar terjadi peningkatan pemahaman dan penerapan Asesmen Nasional dan instrument-instrumennya. Tim pengabdian kemudian berjejaring dengan Instruktur Nasional Kementerian Pendidikan dan Kebudayaan untuk Wilayah Maluku dan Indonesia Timur untuk mendapatkan narasumber dalam kegiatan dimaksud. Demikian juga tim pengadian menyebarkan undangan, membuat flyer, mempersiapkan materi dan lain sebagainya.

\subsection{Pelaksanaan}

Pelatihan untuk Pemahaman dan penerapan Asesmen Nasional (AKM, Survei Karakter dan Survei Lingkungan Belajar) sebagai kegiatan pengadian kepada masyarakat Program Studi Pendidikan Bahasa Inggris FKIP Unpatti di laksanakan pada tanggal 19 Agustus 2021 dengan narasumber tenaga ahli instruktur Nasional pelaksanaan Asesmen Nasional. Pelatihan ini dihadiri oleh 40 orang peserta yang adalah guru dan kepala sekolah di kecamatan Salatuhu Kabupaten Maluku Tengah. Pelatihan dibagi atas beberapa sesi yang diselingi dengan sesi tanya jawab agar materi bisa dipahami dengan baik oleh para peserta.

\subsection{Evaluasi}

Tahap evaluasi dilakukan dengan questionnaire yang dijalankan dengan menggunakan bantuan Google Form. Evaluasi ini ditujukan untuk mendapatkan gambaran kepuasan atas pelaksanaan kegiatan dan materi serta umpan balik dari peserta mengenai Asesmen Nasional (AN)

\section{HASIL DAN PEMBAHASAN}

Asesmen Nasional adalah evaluasi yang dilakukan oleh pemerintah untuk pemetaan mutu sistem pendidikan pada satuan tingkatan pendidikan dasar dan menengah. Evaluasi tersebut menggunakan instrument: asesmen kompetensi minimum, survei karakter, dan survei lingkungan belajar. Asesmen Nasional perlu dilakukan untuk meningkatkan mutu pendidikan. Jadi Asesmen Kompetensi Minimum (AKM) adalah salah satu bagian dari Asesmen Nasional (AN).

Selama ini kita menggunakan Ujian Nasional (UN), jadi apa perbedaan antara UN dan AN (AKM)? UN mengacu pada sensus seluruh murid, sedangkan AKM pada Asesmen Nasional mengacu pada sensus sekolah dengan sampel murid. Asesmen ini dirancang untuk menghasilkan informasi akurat untuk memperbaiki kualitas belajar-mengajar, yang pada 
gilirannya akan meningkatkan hasil belajar murid. Berbeda dengan UN yang hanya diikuti oleh semua siswa tingkat akhir. Tes tersebut hanya berdasarkan pada literasi (bahasa), numerasi (matematika), dan karakter. Dengan pelaksanaannya yang berada di tengah jenjang. Hal ini bertujuan sebagai pemetaan dan penilaian lebih awal pencapaian belajar anak, jadi masih ada waktu bagi sekolah dan guru untuk melakukan perbaikan sebelum anak lulus.

Beberapa tantangan bagi sekolah, yaitu harus adanya kesiapan baik dari dari perangkat dan jaringannya, proktor dan teknisi yang terampil, sarana prasarana seperti server, komputer, dan lain-lain. Kemampuan guru untuk menyampaikan hal-hal terkait AKM yang soal-soalnya cukup berbeda dari apa yang disampaikan oleh para guru mata pelajaran juga menjadi tantangan dalam menghadapi Asesmen Nasional ini.

Tantangan lain bersumber dari mindset dan pemahaman sekolah, guru, siswa dan orang tua. Masih ada pemahaman yang kurang tepat pada sebagian masyarakat, karena pengalaman yang melekat dengan Ujian Nasional. Masyarakat sepertinya masih menganggap Asesmen Nasional ini seperti UN yang harus dipersiapkan dengan baik, sehingga tidak mengherankan bila di daerah didapati beredarnya buku kiat-kiat sukses mengerjakan Asesmen Nasional.

Selain itu ada pula pihak sekolah yang merasa perlu mempersiapkan siswanya menghadapi Asesmen Nasional karena hasil Asesmen Nasional berpengaruh pada guru, kepala sekolah, pengawas dan pemerintah daerah. Sehubungan dengan permasalahan ini, diseminasi informasi terkait Asesmen Nasional diperlukan untuk meluruskan pemahaman yang kurang tepat pada masyarakat maupun sekolah tersebut.

Demikian juga dengan situasi pandemi Covid-19 yang belum sepenuhnya terkendali (selesai), tantangan berikutnya adalah masih banyak daerah yang dalam kondisi Pemberlakuan Pembatasan Kegiatan Masyarakat (PPKM) level 3 dan 4 sehingga menyulitkan dalam pelaksanaan Asesmen Nasional pada September dan Oktober ini. Karena Asesmen Nasional ini bukan UN yang menjadi syarat kelulusan yang harus dilaksanakan segera dan serentak, bagi daerah yang masih belum siap untuk menyelenggarakan Asesmen Nasional kiranya tidak perlu dipaksakan dan bisa ditunda sampai situasi yang lebih memungkinkan.

\section{KESIMPULAN DAN HASIL EVALUASI}

Pelaksanaan Pengadian kepada Masyarakat Program Studi Pendidikan Bahasa Inggris FKIP-Unpatti tahun 2021 lewat pelaksanaan kegiatan Pelatihan Pemahaman dan penerapan Asesmen Nasional (AKM, Survei Karakter dan Survei Lingkungan Belajar) dapat dikatakan berhasil. Kuesioner uman balik kepuasan kegiatan memperlihatkan bahwa semua peserta merasa bahwa tema dan materi yang disampaikan sudah tepat sasaran sesuai dengan yang dibutuhkan dan juga merasa puas dengan penyampaian materi dalam pelatihan. 


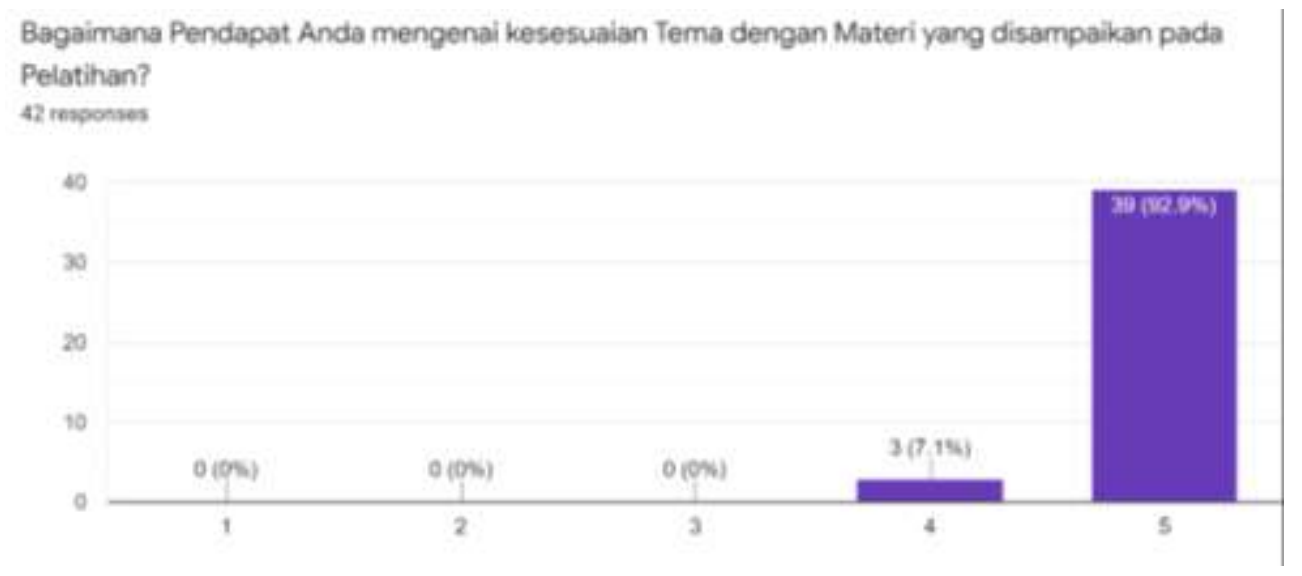

Gambar 2 Tingkat Kepuasan atas Materi pelatihan

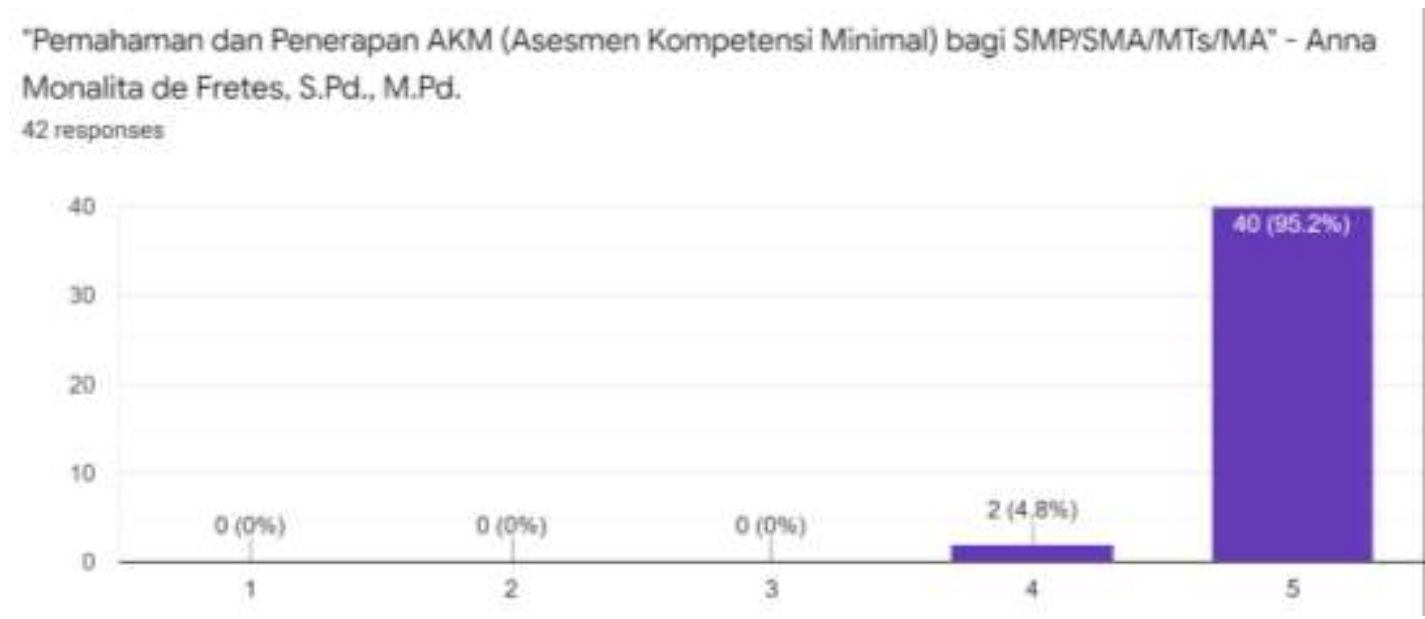

Gambar 3 Umpan balik kepuasan terhadap penyampaian materi

Beberapa kesimpulan yang diperoleh lewat kegiatan ini adalah

1. Tingkat Pemahaman mengenai apa itu Asesmen Nasional dan Instrumen-Instrumennya seperti (AKM, Survei Karakter dan Survei Lingkungan Belajar) masih belum setara antara para guru, kepala sekolah, siswa dan orang tua.

2. Guru merasa masih membutuhkan pelatihan untuk meningkatkan pemahaman dan bagiamana mempersiapkan sekolah mereka menghadapi AN.

3. Pelatihan ini telah mampu membangun pemahaman bagi semua peserta pelatihan, memberikan kesempatan berdiskusi dan bertanya untuk memperjelas semua aspek yang berkaitan dengan AN.

4. Dosen sebagai tim pelaksana pengabdian masyarakat juga menimba ilmu yang berharga mengenai skema evaluasi Pendidikan terbaru yang berlaku di Indonesia. Hal ini akan sangat penting bagi dosen yang sejatinya adalah mitra Pendidikan dengan guru. Terutama bagi dosen-dosen di Fakultas Keguruan dan Ilmu Pendidikan.

Kegiatan pengabdian kepada masyarakat ini dilakukan berdasarkan pemahaman bahwa Masih banyak guru yang belum memahami Asesmen Nasional (AN) dan instrumenintrumennya terutama AKM atau Asesmen Kompetensi Minimum yang merupakah salah satu instrumen dari Asesmen Nasional pangganti UN. AN dan AKM ini baru mulai diterapkan 
tahun 2021. Februari 2021 di Maluku baru dilakukan AKM dalam bentuk Simulasi. Untuk itu, diperlukan pendampingan dan penguatan kapasitas guru untuk memahami dan menerapkan asesmen ini. Pelatihan ini telah berkontribusi untuk mengedukasi dan meningkatkan pemahaman para guru dan kepala sekolah di Kecamatan Salahutu Kabupaten Maluku Tengah. Para peserta kegiatan juga mengekspresikan apresiasi mereka terhadap kegiatan pelatihan ini dan berharap masih akan ada banyak pelatihan mengenai Asesmen Nasional (AN). Demikian juga, dibutuhkan adanya kemitraan dan kerjasama antara FKIP dan pihak sekolah serta instruktur nasional untuk melanjutkan pelaksanaan pelatihan teknis dan sosialisasi seperti ini.

\section{REFERENCES}

Kemdikbud. (2021, July 12). Peraturan Menteri Pendidikan dan Kebudayaan Nomor 17 Tahun 2021 Tentang Asesmen Nasional. Retrieved from Database Peraturan BPK RI: https://peraturan.bpk.go.id/Home/Details/175175/permendikbud-no-17-tahun-2021

Kementerian Pendidikan Nasional Indonesia. (2010). Permen Pendidikan Nasional No. 47 tahun 2010 tentang STANDAR KOMPETENSI LULUSAN BAHASA INGGRIS. Jakarta: Kementerian Pendidikan Nasional Indonesia.

Pusat Asesmen dan Pembelajaran. (2021, April 19). Asesmen Nasional sebagai Penanda Perubahan Paradigma Evaluasi Pendidikan. Retrieved from Pusat Asesmen dan Pembelajaran: Balitbang dan Perbukuan Kementerian Pendidikan dan Kebudayaan: https://puspendik.kemdikbud.go.id/konten/asesmen-nasional-sebagai-penandaperubahan-paradigma-evaluasi-pendidikan

Rokhim, D. A., Rahayu , B. N., lfiah, L. N., Peni, R., Wahyudi, B., Wahyudi , A., . . Widarti, H. R. (2021). Analisis Kesiapan Peserta Didik dan Guru pada Asesmen Nasional (Asesmen Kompetensi Minimum, Survey Karakter, Dan Survey Lingkungan Belajar). JAMP: Jurnal Administrasi dan Manajemen Pendidikan, 4(1), 61-71. Retrieved October 2021, from http://journal2.um.ac.id/index.php/jamp/article/view/18042 